\title{
THE BLOOD-SUGAR IN CONVULSIONS OF INFANCY AND CHILDHOOD
}

\author{
BY
}

\author{
MARGARET B. MACLEAN, M.B., Ch.B.* \\ (From the Department of Paediatrics, Glasgow University, and the \\ Biochemical Laboratory, Royal Hospital for Sick Children, Glasgow.)
}

It has long been recognized that severe convulsive attacks are followed by depletion of the carbohydrate reserves of the body. Indeed one of the experimental methods of exhausting the glycogen of the tissues is by inducing convulsions by the administration of strychnine or other similar drugs. Clearly in these circumstances the reduction of available carbohydrate is the result and not the cause of the convulsion. Following on the recognition of hyperinsulinism as a cause of convulsions, however, the possibility has arisen that hypoglycaemia may be an etiological factor in the production of convulsions in infancy and childhood and there is no doubt that convulsions due to this occasionally occur.

Two cases have been recorded by Kramer, Grayzel and Solomon ${ }^{1}$, and Josephs ${ }^{2,3}$ has suggested that the combination of fever and a short fast may produce a state of hypoglycaemia which may explain the convulsions occurring at the onset of an acute infection. Other workers, however, while noting the presence of hypoglycaemia in the post-convulsive state have hesitated to attribute the seizure to the disturbance in carbohydrate metabolism. Griffiths ${ }^{4}$ noted the association of hypoglycaemia with convulsions but was not sure whether the low blood-sugar was the cause, the result or merely coincident with the convulsion. Higgins ${ }^{5}$ observed hypoglycaemia following convulsions in two new-born babies. Fleming, Herring and Morris ${ }^{6}$ reported three patients who were admitted to hospital comatose and had either glycosuria or a raised blood-sugar which in two of them was followed by hypoglycaemia, and Darrow ${ }^{7}$ recently reported two examples of recurring convulsions in mentally defective children in whom hypoglycaemia was frequently noted but on two occasions shortly after a convulsion the klood-sugar was found to be high. It was found that in the hypoglycaemic phase these children did not respond well to glucose.

The suggestion that idiopathic or epileptic convulsions of infancy and childhood are caused by a state of hypoglycaemia at first sight seems unlikely, for true hypoglycaemic convulsions arising, for example, from over-dosage with or from an excessive production of insulin are of a different nature from the ordinary convulsions of childhood. Frequently the hypoglycaemic fit is preceded by a period of fatigue, malaise, hunger, fear, negativism, confused speech and automatism-none of which is a feature of convulsions due to other causes. While the convulsion itself is indistinguishable from any other, these prodromal symptoms as well as the ready and complete recovery following the administration of

*The work was carried out during the tenure of a Reid Stewart Scholarship. 
adrenaline or glucose seem to differentiate such seizures. Much that is equivocal has been written on the sugar content of the blood in idiopathic epilepsy.

Daly, Pryde and Walker ${ }^{8}$ thought there might be some relationship between low values and the onset of seizures but found the results inconclusive. Lennox and $\mathrm{Cobb}^{9}$, after examining a large number of cases, came to the conclusion that the great majority of epileptics presented no disturbance of carbohydrate metabolism and that any change in the sugar content of the blood following a convulsion was merely the result of the increased muscular exertion and the asphyxia. Nielsen ", hand, found that about 90 per cent. of cases of idiopathic epilepsy showed a tendency to hypoglycaemia though he did not consider that hypoglycaemia alone was sufficient to precipitate an attack. This contention was supported by Tyson, Otis and Joyce ${ }^{11}$, who found a tendency in epileptics as a whole towards subnormal fasting blood-sugar values. These authorities drew their conclusions from the study of sugar tolerance curves in epileptics and paid less attention to the blood-sugar level during or shortly after a convulsion.

\section{Present investigation}

In view of the confusion of opinion regarding the rôle of hypoglycaemia in the etiology of convulsions in childhood, blood-sugar estimations were made in a series of children admitted to hospital on account of convulsions and an attempt was made to follow the changes occurring in the bloodsugar level from the beginning of a convulsion till some hours after it had ceased. Unfortunately it was never possible to obtain a blood-sugar reading immediately before a convulsion. The patients were of ages varying from two days to eleven-and-a-half years and the seizures were due to various causes, such as birth injury, spasmophilia, meningitis, epilepsy or acute infections. The blood-sugar was estimated by a modified Folin and $\mathrm{Wu}$ method.

Fifty patients were examined and of these three were examined on two separate occasions making in all fifty-three observations. The blood-sugar was estimated at frequent intervals-often hourly. The results are given in an abbreviated form in table 1 . This shows the maximum and minimum blood-sugar values during four periods, (1) from the onset until three hours, (2) from the fourth till the twelfth hour, (3) from the thirteenth till the twenty-fourth hour and (4) from the twenty-fourth till the fortyeight hour after the convulsion. It will ke seen that high blood-sugar values occur most frequently in the first three hours after the convulsion and that these often persist into the second period. The hypoglycaemic readings are scattered throughout the last three periods but occur most frequently in the second of these. It appears, therefore, that there are as a general rule two phases, a state of hyperglycaemia followed by one of hypoglycaemia. A blood-sugar level of more than $180 \mathrm{mgm}$. per cent. was taken as indicating hyperglycaemia and one of less than $60 \mathrm{mgm}$. per cent. as hypoglycaemia. The following is a typical case (case 16).

E. F., a girl, aged one-and-a-half years, was delivered by Caesarean section and appeared healthy at birth. She throve and developed normally and had always been healthy except for an attack 
THE BLOOD-SUGAR IN CONVULSIONS

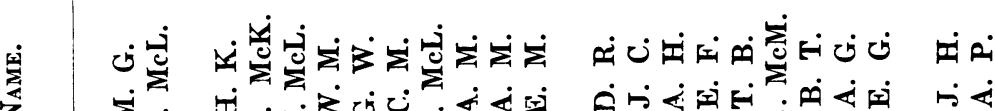

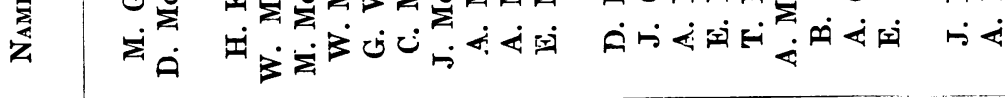
安 -N 
of chicken-pox six months before admission. During the night before admission to hospital she vomited once and slept badly. At 6 a.m. on the day of admission she was found unconscious and from then until she was admitted to hospital had frequent attacks of generalized rigidity each lasting for about five minutes. On admission at 8.30 a.m. she was still unconscious and breathing stertorously. She was a small, pale child and on examination no abnormality was found in the heart, lungs or abdomen. The knee jerks were active and the plantar responses extensor. The rectal temperature was $101 \cdot 8^{\circ}$. She recovered consciousness at noon but remained drowsy all day. Next day she appeared quite well. The blood-sugar content was estimated at half-hourly intervals for the first few hours and then hourly throughout the day. Some of the readings are shown in table 2 .

TABLE 2.

\begin{tabular}{c|c|c|c|c|c|c|c|c}
\hline $\begin{array}{c}8.45 \\
\text { A.M. }\end{array}$ & $\begin{array}{c}9.45 \\
\text { A.M. }\end{array}$ & $\begin{array}{c}10.45 \\
\text { A.M. }\end{array}$ & $\begin{array}{c}11.45 \\
\text { A.M. }\end{array}$ & $\begin{array}{c}12.45 \\
\text { A.M. }\end{array}$ & $\begin{array}{c}2.15 \\
\text { P.M. }\end{array}$ & $\begin{array}{c}3.15 \\
\text { P.M. }\end{array}$ & 4 P.M. & 5 P.M. \\
\cline { 1 - 3 } $232 \cdot 6$ & 114.9 & $92 \cdot 6$ & 74.6 & 113.6 & 84.7 & 58.1 & 49.5 & $\begin{array}{c}42 \cdot 8 \text { mgm. } \\
\text { per cent. }\end{array}$ \\
\hline
\end{tabular}

At 9 a.m. the next morning the blood-sugar was still rather low, $65 \cdot 8 \mathrm{mgm}$. per cent. but by the next day it had risen to a normal leyel of $89 \cdot 3 \mathrm{mgm}$. per cent.

The hyperglycaemic phase

Twenty-six cases were examined within three hours of the onset of a convulsion and eleven of these showed a blood-sugar content above 180 mgm. per cent. In one of the cases this was observed on two occasions (case 12). Fifteen of the patients who were examined within three hours of a convulsion did not show hyperglycaemia but in six the blood-sugar level ras over $130 \mathrm{mgm}$. per cent. and in the remaining nine no value below $80 \mathrm{mgm}$. was found. In many of these it was impossible to say whether food had recently been taken and on this account the moderate rise observed could not be definitely attributed to the convulsion. Of the cases which did not show hyperglycaemia, three had mild convulsions. This may account for the absence of reaction since the highest blood-sugar readings were usually obtained when the convulsions were severe and prolonged. Further it is probable that the hyperglycaemic state was missed in some of the cases as they were not examined soon enough after the onset of the convulsion. This was almost certainly what occurred in case 43 , for urine passed eight-and-a-half hours after the convulsion contained sugar when the blood-sugar content was $78 \cdot 1 \mathrm{mgm}$. per cent.

The hypoglycaemic phase

Hypoglycaemia was found at one time or another in twenty-five of the patients. That this was a temporary disturbance is shown by the fact that in three sugar tolerance tests were carried out and in eight others the fasting blood-sugar was estimated during convalescence. In none of these was the curve abnormal or the fasting blood-sugar unduly low. Hypoglycaemia occurred commonly in the second period, i.e., four to twelve 
hours after the convulsion but in some at later periods. In one patient (case 29) it occurred in the first period; this was in a child aged nine months, admitted with profound toxaemia due to ileo-colitis. The child had a convulsion on admission to hospital and the blood-sugar then was 103.1 mgm. per cent. She rapidly became moribund and the blood-sugar three hours later had fallen to $33.0 \mathrm{mgm}$. per cent. The child died four hours after admission to hospital and the blood-sugar immediately after death was found to be $12 \mathrm{mgm}$. per cent. Low readings below $30 \mathrm{mgm}$. per cent. were obtained on seven occasions but hypoglycaemic symptoms were never observed. As with the hyperglycaemic phase, the hypoglycaemia, which is often transient, may have occurred in some of the patients in the interval between two observations and consequently may have been missed.

The disturbances in the blood-sugar content described above could not be definitely related to any particular disease nor to any particular type of convulsion; hyperglycaemia, however, seemed to occur most commonly in cases of tuberculous meningitis and intracranial injury in new-born babies seemed most prone to lead to profound' '-oglycaemia. Of six cases of meningitis examined within three hours of the convulsion four showed hyperglycaemia and all the six cases of intracranial injury in the series had at one time or another marked hypoglycaemia; five of these infants recovered and in the course of convalescence there was a gradual rise in the blood-sugar to the normal level.

\section{Discussion.}

It would appear, therefore, that during or immediately after a convulsion the blood-sugar percentage is frequently raised and that it falls rapidly, sometimes to a low level, remains low for several hours or days and then rises to the normal level. These results confirm the observation of Josephs and others that there is a state of hypoglycaemia following a convulsive attack. Their failure to note the initial rise, except in a few instances, was probably because the observations were, as a rule, not made sufficiently soon after a convulsion to catch the hyperglycaemic phase. The recognition of the biphasic nature of the change provides a possible explanation of its etiology. It seems probable that the initial rise is due to the profound disturbance of the central nervous system occasioned by the convulsion and that this causes mobilization of glucose from glycogen-a condition similar to that produced by Bernard's diabetic puncture.

Titus, Willets and Lightbody ${ }^{12}$ noticed a rise in blood-sugar immediately following the convulsions of eclampsia, in some cases slight and in others marked, but concluded that this was only a physiological and transient hyperglycaemia following the strenuous muscular exertion. Romcke and Skouge ${ }^{13}$ have described thirteen cases of cerebral haemorrhage in all of whom there was hyperglycaemia; they suggest that this was caused by over-secretion of adrenaline from stimulation of the medulla oblongata.

In the present series definite hyperglycaemia was only detected in approximately 40 per cent. of the cases examined within three hours of the convulsion. It may be that in a considerable number the hyperglycaemic phase was missed but it is possible that in others the stimulation was 
insufficient to affect that part of the brain controlling carbohydrate metabolism.

Regarding the subsequent hypoglycaemic phase there are two possible explanations. It may be that the violent muscular exertion uses all the available carbohydrate and the body tissues are left in a state of carbohydrate depletion or that the central stimulation, acting as it does on the suprarenals, leads to exhaustion of adrenaline and in the absence of this to the cessation of glycogenolysis. Against the first suggestion is the fact that the blood-sugar, though it may show a transient rise after a meal, tends to remain low for many hours after the convulsion even though ample carbohydrate has been given in the food. Moreover it is generally recognized that even during complete starvation the blood-sugar does not fall very appreciably below the fasting level owing to the formation of glucose from endogenous sources, presumably protein and fat. In the patients here described, even though the glycogen stores had been reduced to a low level, which was probably not the case as they all received food, there should not therefore have been hypoglycaemia had there been an adequate stimulus for the production of glucose. Lawrence ${ }^{14}$, in a recent paper, has stressed the importance of the adrenal, thyroid and pituitary secretions in 'facilitating the supply of peripheral sugar.' In view of the frequent occurrence of hyperglycaemia prior to the hypoglycaemic phase it seems probable that in many of the present series of patients there was an initial oversecretion with consequent exhaustion of the store of adrenaline. If this reasoning is correct administration of adrenaline should readjust, at any rate temporarily, the level of the bloodsugar. This hypothesis was put to the test on two occasions. Blood-sugar examinations were carried out in the usual way on two children who had had convulsions. When the hypoglycaemic stage was reached adrenaline was injected and the blood-sugar estimations continued at frequent intervals.

The first case in which this procedure was tried was the typical case already described (p. 248). At 5 p.m. when the blood-sugar was $42.8 \mathrm{mgm}$. per cent., 0.25 c.c. adrenaline (1/1000) was injected subcutaneously. Fig. 1 shows the changes that occurred. It will be seen that there was an immediate response. The blood-sugar rose to over $80 \mathrm{mgm}$. per cent. within two hours of the injection and within three hours of the beginning of the experiment had fallen to its original level. As the child had been fasting since noon the rise in the blood-sugar cannot be attributed to the taking of food.

In the second patient (case 2), the initial rise in the bloodsugar level had been missed and observations only began in the hypoglycaemic phase. Some months previously, however, the child had had a similar convulsion and on that occasion the blood-sugar tests had commenced within three hours of the seizure and the hyperglycaemic phase (188.7 mgm. per cent.) had been registered. On the second admission the boy was brought to hospital eighteen hours after a 
Fig. 1.-The blood-sugar after adrenaline. (Case 16.)

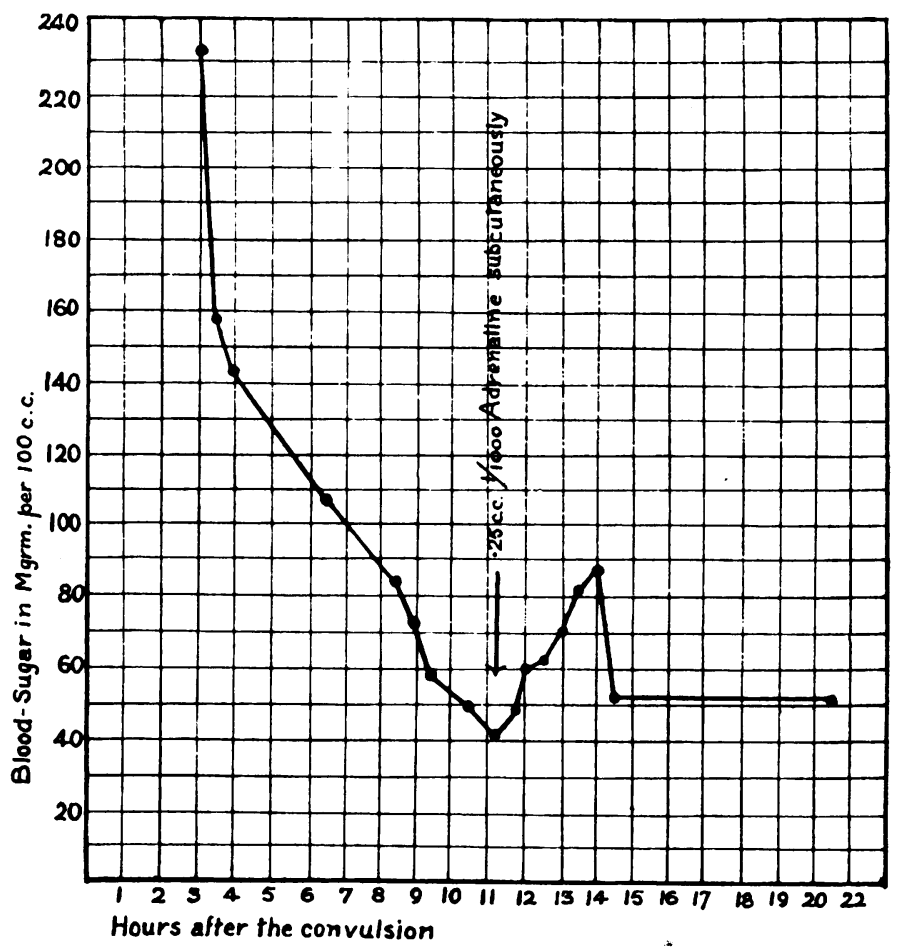

E. F., aged $16 / 12$ years.

Fig. 2.-The blood-sugar changes after adrenaline. (Case 2.)

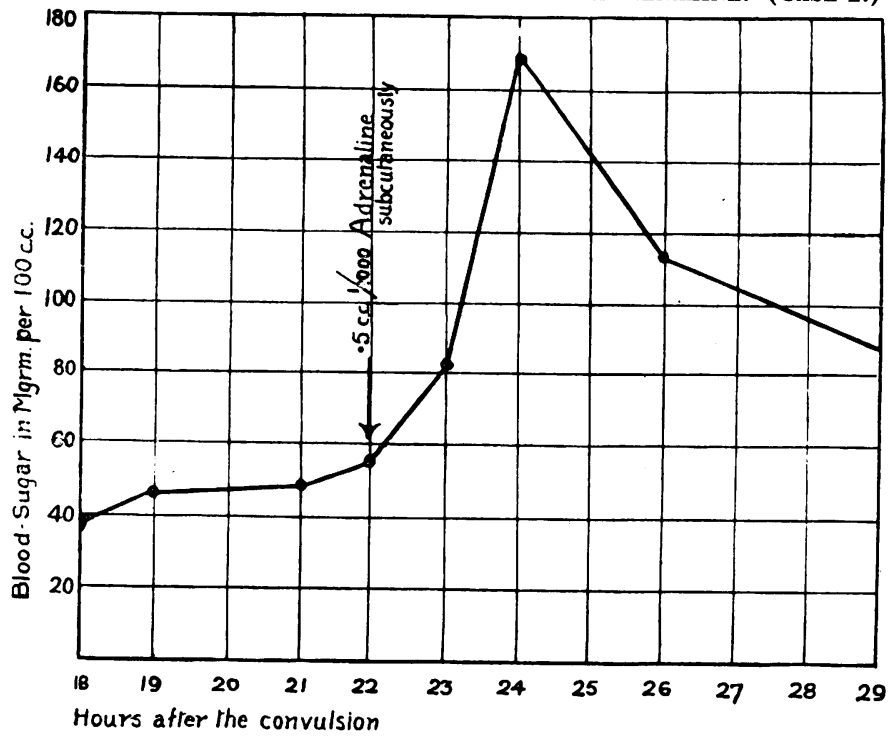

D. McL., aged 5 3/12 years. 
convulsion. At that time he was conscious but drowsy and the bloodsugar level was found to be $36.5 \mathrm{mgm}$. per cent. There can be little doubt that with the second convulsion there had been a rise similar to that which occurred with the previous convulsion. Fig 2 shows the changes that occurred after giving 0.5 c.c. adrenaline (1/1000) subcutaneously during the hypoglycaemic phase. It will be seen that there was an immediate response, the blood-sugar rising to a level of $169 \mathrm{mgm}$. one hour fortyfive minutes after the injection. No food had been given for at least four hours previous to the adrenaline injection. The response to adrenaline in both cases provides strong evidence in favour of the hypothesis that the hypoglycaemic phase following a convulsion is dependent on deficiency of adrenaline and that, during this period, the tissues are able to form glucose when adrenaline is supplied.

\section{Summary.}

1. The blood-sugar content was estimated at frequent intervals after convulsions in fifty children.

2. It was found that when the estimations were done sufficiently soon after a convulsion there was a state of hyperglycaemia in nearly half of the cases.

3. In half the cases a state of hypoglycaemia was found to occur some hours after the convulsion and to persist in spite of taking food.

4. In two cases the administration of adrenaline during the hypoglycaemic phase was followed by a significant rise in the blood-sugar level.

5. The cause of the changes in the blood-sugar concentration is discussed.

\section{Conclusions.}

Except in cases of true hyperinsulinișm it would appear that hypoglycaemia plays no part in the causation of the convulsions of childhood and that the upset in carbohydrate metabolism is the result and not the cause of the convulsions.

Thanks are due to Prof. G. B. Fleming and Dr. N. Morris for suggesting this investigation and for much helpful advice and criticism. Dr. S. Graham kindly afforded opportunity of investigating cases in his wards.

\section{REFERENCES.}

1. Kramer, B., Grayzel, H. G., \& Solomon, C. I., Jour. Ped., St. Louis, 1434, V, 299.

2. Josephs, H., Am. J. Dis. Child., Chicago, 1926, XXXI, 169.

3. Josephs, H., ibid., 1929, XXXVIII, 746.

4. Griffiths, J. P. C., J. Am. Med. Ass., Chicago, 1929, XCIII, 1526. 
5. Higgins, R. A., Am. J. Dis. Child., Chicago, 1935, L, 162.

6. Fleming, G. B., Herring, J. \& Morris N., Arch. Dis. Childh., London, 1935, X 397.

7. Darrow, D. C., Am. J. Dis. Child., Chicago, 1936, LI, 575.

8. Daly, I. De B., Pryde, J. \& Walker, J., Brit. Med. J., London, 1924, i, 232.

9. Lennox, W. G. \& Cobb, S., Medicine, Baltimore, 1928, VII, 105.

10. Nielsen, J. M., Arch. Neurol. \& Psychiat., Chicago, 1934, XXXI, 1055.

11. Tyson, G. N. Jr., Otis, L. \& Joyce, T. F., Am. J. Med. Sci., Philadelphia, 1935, CXC, 164.

12. Titus, P., Willets, E. W., \& Lightbody, H. D., Am. J. Obstet. \& Gyn., St. Louis, 1930, XIX, 16.

13. Romcke, O., \& Skouge, E., Acta Med. Scand., Stockholm, 1931, LXXVII, 210.

14. Lawrence, R. D., Brit. Med. J., London, 1936, i, 749. 